Mojca Schlamberger Brezar

UDK 811.163.6'373.611

Faculté des lettres, Université de Ljubljana

Slovénie

mojca.brezar@ff.uni-lj.si
DOI: $10.4312 /$ vestnik.13.67-90

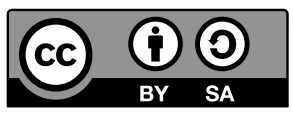

\title{
PRODUCTIVITÉ DES PRÉFIXES ÉTRANGERS DANS LES COMPOSITIONS NOMINALES ET ADJECTIVALES EN SLOVÈNE
}

\section{O INTRODUCTION}

Dans cet article dont l'idée était venue de la part de mon cher collègue Gregor Perko - et que nous n'avons jamais pu écrire ensemble, ayant seulement rassemblé une partie du matériau linguistique à la base du corpus monolingue slovène FidaPlus - il était prévu de voir, par le biais de la méthodologie dans le cadre de la morphologie constructionnelle, si dans le cas des préfixes étrangers nominaux ou adjectivaux, dans la plupart gréco-latins, il s'agit vraiment de la composition (Toporišič 2000 : 194). Une étape dans cette recherche consistait d'en identifier, à travers une analyse du corpus slovène monolingue Gigafida2.0, la productivité.

Nous mettons en question la liste des « morphèmes dérivationnels étrangers » décrite dans la Grammaire slovène (Toporišič 2000), en nous posant la question s'il s'agit vraiment des morphèmes dérivationnels étrangers ou simplement des emprunts du mot entier. La recherche est complétée par les exemples tirés du corpus slovène qui confirment ou infirment notre hypothèse ${ }^{1}$.

\section{MORPHOLOGIE MORPHÉMATIQUE, MORPHOLOGIE CONSTRUCTIONNELLE, MORPHOLOGIE DÉRIVATIONNELLE}

Dans l'approche structuraliste, l'approche morphologique morphématique présuppose le découpage en morphèmes. La morphologie lexicale, qui traite traditionnellement de la forme et de la formation des mots en termes de dérivation et composition, suit deux perspectives complémentaires, synchronique et diachronique (Riegel et al. 1994 : 539). Les mots complexes sont constitués de deux ou plusieurs mots ou morphèmes. Dans les recherches linguistiques slovènes, l'approche que prend Toporišič est structurelle, il part

1 Cette recherche est menée dans le cadre du programme de recherche P6-0215 Slovenski jezik: bazične, aplikativne in kontrastivne študije, financé par l'Agence nationale slovène de recherche ARRS. 
des bases de la morphématique combinatoire, qui parfois ne peut pas entièrement rendre compte des problèmes de composition des mots. Le chapitre Besedotvorje, entièrement consacré au phénomène mentionné, comporte quelques problèmes méthodologiques concernant l'introduction des approches diachroniques et des analyses étymologiques dans une description purement synchronique (Toporišič 2000 : 194-85 ; Perko, Schlamberger Brezar 2016).

Dans l'optique de la morphologie constructionnelle, introduite dans la linguistique slovène par Gregor Perko (2011), c'est la morphologie qui rend compte aussi bien de la flexion que de la construction de mots nouveaux : il reste à distinguer la morphologie constructionnelle, qui rend compte de tous les procédés de la formation des mots, des procédés de dérivation comprenant la préfixation et la suffixation, de la morphologie flexionnelle, ensemble des relations que peuvent entretenir les différentes formes d'un même lexème - par exemple, selon les langues, le singulier et le pluriel d'un nom, le présent et le futur d'un verbe, le masculin et le féminin d'un adjectif (Creissels, 2015 : 7). La morphologie constructionnelle offre une nouvelle approche : selon Creissels (2015), on peut désigner du terme général de morphologie constructionnelle l'ensemble des relations que peuvent entretenir des lexèmes différents mais apparentés (appartenant selon la terminologie traditionnelle à la même 'famille de mots'), un lexème construit étant un lexème dont la formation peut se décrire à partir d'un ou plusieurs autres lexèmes. Les grammaires traditionnelles, généralement structurelles, parlent de 'formation des mots', où 'mot' doit être compris au sens de 'lexème' (Creissels 2015 : 6).

Le lexème, défini comme une unité lexicale abstraite des marques de flexion, est donc l'unité de base et de sortie (cf. notamment, Matthews 1974 ; Aronoff 1994 ; Fradin 2003). Il comprend les deux faces indissociables du signe, une face matérielle (phonique ou gestuelle) et une face abstraite qui enregistre des informations syntaxiques et sémantiques nécessaires pour rendre compte de la combinaison des lexèmes entre eux, que ce soit en morphologie ou en syntaxe (Desmets, Villoing 2010).

Les affixes sont, au sens général du terme, des morphèmes liés qui fonctionnent comme des constituants du mot. Ils sont nécessairement attachés à un radical ou à une base simple ou déjà pourvue d'un affixe ; celui-ci peut être flexionnel ou dérivationnel (Riegel et al. 1994 : 537). Le statut de l'affixe n'est pas toujours clair : ce qui présente, en synchronie, un radical, peut être considéré, en diachronie, comme un mot composé, formé de plusieurs morphèmes (affixes, préfixes, suffixes, qui ne le sont plus aujourd'hui) - et ce qui peut présenter, au sein d'une langue, un mot composé, peut être tenu dans une autre pour une base simple.

Selon les travaux de D. Corbin (1987), seuls les mots composés ou dérivés sont d'authentiques mots construits dont la structure morphosémantique est analysable selon les règles propres à la composante lexicale de la langue.

La description des procédés de formation des mots dans l'approche de la morphologie constructionnelle a déjà été présentée sur le modèle des préverbes dans les emprunts 
grecs ou latins commençant par $a$-, de-, dis-, eks-, in-/im-, inter-, re-dans Perko, Schlamberger Brezar (2016). Nous avons voulu démontrer que les préfixes (ou préverbes) ne sont pas ou plus productifs dans les opérations de la formation des mots, pour ainsi dire ne sont plus « vivants », et que les mots qui comportent ces préfixes sont, dans la perspective synchronique, généralement à traiter comme les emprunts, venus en slovène par le biais de l'allemand, et non pas comme les mots composés, ce que nous avons démontré sur les exemples des verbes abdicirati (abdiquer), deformirati (déformer), demaskirati (démasquer), imobilizirati (immobiliser), interpretirati (interpréter), etc. (Perko, Schlamberger Brezar 2016).

\section{2}

\section{PHÉNOMÈNE DE PRODUCTIVITÉ}

La productivité en linguistique est l'action d'un locuteur natif « de produire de nouvelles expressions nominales, adjectivales et autres, expressions qui ne se sont pas encore rencontrées dans les phrases réalisées » (https:/www.cnrtl.fr/definition/productivit $\% \mathrm{C} 3 \% \mathrm{~A} 9$ ) à l'aide des moyens linguistiques existants.

Dans la morphologie constructionnelle, la notion de productivité (Perko, Schlamberger Brezar 2016) est liée à des notions comme la disponibilité d'opérations constructionnelles d'affixation (pré- et suffixation), de prédictivité sémantique, phonologique, morphologique et syntaxique des mots composés et leur " régularité » par rapport au prototype. L'opération de la morphologie constructionnelle doit être sémantiquement, phonologiquement, morphologiquement et syntaxiquement transparente (voir aussi Perko, Schlamberger Brezar 2016). Notons aussi que, selon Matthews (1974 : 76), les lexèmes assurant la productivité peuvent être qualifiés d'établis ou potentiels, laissant place à la créativité des locuteurs.

Quelques auteurs (Dressler 2000) mettent aussi en évidence le critère de non-intentionnalité, ce qui signifie que les locuteurs natifs sont capables de former des mots nouveaux - non lexicalisés, spontanément, sans l'aide des opérations métalinguistiques - et de les comprendre. C'est la productivité qualitative (Dal 2003) qui va, ces dernières années, de pair avec la productivité quantitative (p. ex. Baayen 1993), basée sur l'analyse des opérations constructionnelles dans les corpus par les formules statistiques. Cette approche ne sera pas utilisée dans la présente recherche.

La définition du préfixe qu'on trouve dans le livre encyclopédique sur la langue slovène de Toporišič Enciklopedija slovenskega jezika (1992 : 208), illustre bien la nature morphématique de son approche à la formation des mots, basée sur la segmentation linéaire, où font défaut les critères de distinction entre les affixes et la racine et aussi les consignes indiquant comment les reconnaître à l'intérieur du mot. Les facteurs de la productivité ne sont non plus pris en compte. 


\section{DESCRIPTION DES CORPUS UTILISÉS ET DE L'APPROCHE MÉTHODOLOGIQUE}

Entre 2004 et 2006, la recherche était menée dans le corpus FidaPlus, auquel on a activement contribué avec des textes entre 1996 et 2006, et qui était ensuite remplacé par les corpus Gigafida en 2012 et Gigafida 2.0 en 2019 (https://jezikovna-politika.si/opremljenost/jezikovni-opis/korpusi/), sur lesquels nous avons continué à mener notre analyse. La différence entre les deux corpus est dans la taille et la normativité : si le corpus FidaPlus était composé des textes revus par les lecteurs-réviseurs ${ }^{2}$ et comprenait au total 621 millions de mots (https://sl.wikipedia.org/wiki/FidaPLUS), le corpus Gigafida 2.0 en contient 1134693933 dans 38310 textes parus entre 1990 et 2018. Il se veut un corpus de slovène standard (https://www.cjvt.si/viri-in-orodja/besedilni-korpusi/), pourtant les textes, surtout ceux extraits de l'Internet, n'ont pas subi de révision linguistique. Ce fait peut influencer les résultats de l'analyse.

Notre approche méthodologique consiste en l'analyse de la productivité des préfixes dits étrangers dans la grammaire de Toporišič. Dans l'article précédent (Perko, Schlamberger Brezar 2016), l'analyse portait sur la productivité des préfixes verbaux. Dans cet article, nous allons mettre en valeur les préfixes étrangers d'origine gréco-latine, ajoutés aux noms et aux adjectifs dans le procédé de composition.

Toporišič, dans le chapitre Composition des noms (Toporišič 2000 : 194-195), énumère les préfixes suivants : a, ante, anti, eks, hiper, hipo, infra, inter, intra, ko, kontra, meta, sin, sub, super, supra, trans, ultra. Les mêmes sont utilisés pour la composition des adjectifs (Toporišič $2000:$ 200-201).

Toporišič parle aussi du caractère motivé des mots composés, consistant en une base et un affixe (dans notre cas préfixe, mais parfois aussi suffixe) : la motivation, dans les exemples cités, est certaine pour un locuteur natif - sin-ko (petit fils), mater-in (de la mère), pre-mlad (trop jeune). Il parle aussi de la productivité de certaines parties du discours et des moyens où il prend en compte des critères qualitatifs comme ceux présentés ci-dessus. Mais ces bases notionnelles ne sont pas prises en compte dans l'énumération des préfixes nominaux et adjectivaux que nous verrons dans l'analyse pratique présentée ci-dessous.

Les critères auxquels doivent répondre ces préfixes pour obtenir le statut de lexème, selon les bases de la morphologie constructionnelle, sont leur productivité et leur capacité d'être employés avec les lexèmes, notamment noms et adjectifs, d'origine slovène. Notre but sera de les analyser dans une approche quantitative et qualitative aux données, dans le cadre du corpus Gigafida 2.0 (https://viri.cjvt.si/gigafida).

2 Le lecteur-réviseur (lektor en slovène), personne qualifiée pour la révision des textes et leur conformité à la norme, faisait régulièrement partie des maisons éditoriales il y a 10 ans. Aujourd'hui, seuls les articles qui voient le jour sous forme papier sont relus et normalisés. 
Dans cette partie, nous essayerons d'analyser les préfixes cités ci-dessus dits étrangers et voir leur productivité dans le corpus Gigafida 2.0. La productivité sera démontrée dans les combinaisons avec les lexèmes d'origine slovène qui rendront compte de la créativité linguistique. Par la suite, chaque préfixe étranger en liaison avec les noms et les adjectifs sera analysé quantitativement et qualitativement et illustré par un tableau tiré du corpus.

\section{$a-/ a b-$}

On ne peut pas, à la base de l'analyse des corpus, voir la productivité de $a$ - et son allomorphe $a b$ - comme préfixe. Notamment, les mots commençant par $a$ en slovène sont généralement des emprunts (sauf $a b c$, abeceda, alphabet) et quelques onomatopées comme les interjections $a h, a h a, a j$, aja, ajati, av, alors les deux exemples donnés par Toporišič, amorala et abiogeneza, sont de rares emprunts qui s'opposent à leurs contraires morala et biogeneza, auxquels on pourrait ajouter abuzus (contre usuzs). Il en va de même pour son allomorphe ab-normalen (qui s'oppose à normalen). Ce préfixe n'est pas productif.

\section{ante-}

Dans le corpus Gigafida2.0, ante a 125 occurrences. D'après l'analyse des exemples, ante n'apparaît pas comme préfixe mais en tant que préposition d'emprunt, surtout dans les expressions toutes faites ou citations comme ante portas, ex-ante (voir la liste ci-dessous).

I sicer odvisne tudi od drugega načrtovanega sklada - sklada ex- ante shem za zajamčene vloge, saj bosta sklada delovala komf əvanju konkurence, ampak je v skladu s svojimi pristojnostmi ex ante regulatorja v nadzornem postopku zgolj zavarovala z usta mo ravno omenili tiste, ki prezgodaj izlivajo semena (nekateri že ante portas, se pravi pred durmi oziroma še preden ga vtaknejc I ni ra ču nal niš ki igri Lu I a 3D in N e ed for s peed mo st w ante d p rod am. Tel.: 04 0/554 - 637. Email: t ad ejro bic@ gm mur bi se smejali. V najhujši obliki ji strokovno rečejo ejakulacija ante portas, pred vrati, z drugimi besedami pa - gre za tiste ne: etna omrežja in jih takoj uporabili za politične asasinacije. Šakal ante portas! Na Hrvaškem so skušali s Facebookom zrušiti pre ısti grad (Herchlinus Cranpergarius... construi fecit unam turrim ante portam castri inferiori de Vipaco), leta 1386 pa ga je od vit ske vlade. Večina tujih opazovalcev že razpreda o Berlusconiju » ante portas «.

Jar pa so si vsi prestrašeni evropski analitiki pulili lase. Hannibal ante portas! Evropa se obrača na desno. Skrajno desno. kot da ti pameten med vso to orgijo nespameti. Vzpostaviti "status quo ante ", postaviti stvari v stanje, kakršno je bilo pred avgustom 1 
:avnih pomoči se bodo odrazile tudi v slovenski praksi, ki pri »ex ante « int »ex post « merjenju zaostaja za drugimi državami.

Ta mora imeti pred očmi, da se proračunske krize ne rešuje »ex ante «, vnaprej, kot to sedaj počne ta vlada, ampak »ex post «, :

redzgodovine tega, kar bi lahko imenovali zgodovina mentalitet ante litteram bilo delo G. Lefebvra La Grande Peur, malone poli

Tableau 1 - ante

\section{anti-}

Le préfixe anti a 3561 concordances dans le corpus sous les formes suivantes : 4812 occurrences anti, 1198 occurrences Anti (avec une majuscule), les autres occurrences sont distribuées entre anen, ant/Ant, anta/Anta ${ }^{3}$. Il était isolé comme seul productif dans le corpus FidaPlus entre 2006 et 2008 avec 56186 concordances pour la recherche anti*, parmi lesquelles Antič, antika, antičen, antikvariat, antilopa, Antigny, Antili, Antikor, Antibes, antimon, Antigona apparaissaient comme des mots non-construits. Anti est perçu comme préfixe par les locuteurs et les journalistes, ce qui exprime les formations discursives avec le nom propre dans le journal Mladina ${ }^{4}$ comme anti-Mastnak ou anti-Janša ${ }^{5}$; ces formations témoignent donc de sa productivité. La plus fréquente combinaison avec les noms propres est antijanša (écrit aussi anti Janša, antiJanša ou antijanša) qui trouve aussi son contraire dans projanša dans la citation : umetno vzdrževanje programa antijanša - projanša (maintenance artificielle du programme projanša et antijanša). Ce préfixe apparait aussi en combinaison avec les noms et les adjectifs communs : antijunak (antihéros), antiigra (antijeu), antiženski (antiféminin), anticerkveni (anti-clérical) etc., qui témoignent de sa productivité.

L'orthographe dans le corpus est variable, nous pouvons retrouver les formes antiou anti comme visible dans le Tableau 2 ci-dessous.

ma krščansko prebivalstvo ustanovilo lastne milice, znane kot " anti -balaka", te pa so zakrivile več napadov na muslimane. Skı jegova mati, korporacija Time-Warner, sočasno borila za zvezno anti -trustovsko odobritev akvizicije Turnerjevega medijskega i 0 pred našim štetjem končala antično civilizacijo, torej prevlado Antov , leta 2011 pa se bo po 2500 letih končal cikel rimsko-grš Kje smo? Kam gremo? Ali smo že tam? Satirični ( anti )utopični roman, izšel pri zalo ' bi Ved, 304 strani, broširan : Vodoravno: ugaslost, narkoman, llir, Ant, cimbora, ena, Kati, fango, Ohm, zb, LK, kvartir, duola, tart Za nego zrele kože Bobbi priporoča uporabo ' anti -aging' negovalnih obraznih olj, saj negovalne sestavine ol cionalno nezrelega in nesimpatičnega glavnega junaka (v bistvu anti -junaka) so ta njegov roman pogosto primerjali s Tujcem $\mathrm{nc}$

3 Ici se pose la question des annotations du corpus Gigafida qui donnent des résultats qui ne sont parfois pas liés avec le mot ou la forme recherchée (à voir aussi avec les autres préfixes, notamment eks, ekso).

4 Magazine hebdomadaire à vocation économique, politique, sociale et culturelle.

5 Remarque culturelle : Mastnak est philosophe, Janša politicien. 
lenko, Slovak Jozef Gönci, Američana Matthew Emmons in Mike Anti , Avstrijec Thomas Farnik, Finec Juha Hirvi, Norvežan Hara jizij samouničenja razbrazdanega gospoda Austina. Nečloveška anti glasba, katere cilj je popolno uničenje. Smrt. (666) Vodoravno: atlet, tast, Stritar, olein, postaja, rtina, Anti, Sket, zel, Ejsk, Naum, bon, East, soba, rojak, katolik, aka Idpredsednik Joseph Lieberman, objavila whos who ameriškega anti -bushizma, spisek akademikov, bolj ali manj univerzitetnih a pri Centru Evropa, gradivo so ji poslali telefonisti NatoFona, za anti -NATO zbornik Ne Nato, mir nam dajte pa avtorica še ni sliš mni posli tudi obstajajo po razvitih državah toda le kot poslovna anti kultura, le nekaj procentov od celotnega gospodarstva. K€ loktorat, ož, Mahler, kriza, AN, alt, era, steklovina, kosa, Resen, Ant , kožar, SK, orožar, ato, knez, gnev, Maina, brana, oljar, Rac trok, 8. amarilis, 10. OAS, 11. Bra, 12. mina, 13. netivo, 15. olje, 16. Ant , 17. Rea, 18. Inge, 19. anilin, 22. Omer, 23. ZDA, 24. Ita, 25. r ANKAR (Knjiga) - STUDIO MARKETING/JWT; B08022 NATIKAČI ( Anti aids) - STUDIO MARKETING/JWT

\section{Tableau 2- anti}

\section{eks-}

Le préfixe eks a 695 occurrences où il figure dans la plupart des cas comme mot isolé avec un sens prépositionnel ou adverbial car polyphonique (eks minister (ex-ministre), seks na eks (sex rapide). Comme vrai préfixe, eks est orthographié avec le tiret comme eks- dans 129 cas et avec la majuscule dans 7 cas : eks-minister (l'ancien ministre), etc. Il est limité à des cas isolés nominaux ou adjectivaux signifiant « qui n'est plus en position » : eks-policaj (ancien policier), eks-vojak (ancien soldat), eks-ljubimec (ancien amant), eks-varuh (ancien gardien), eks-komunistični /režim/ (l'ancien régime communiste), ce qui révèle sa productivité (voir le tableau 3 ci-dessous).

ran za ekskurzije. V sredo, 12. junija 1996, sta bili dve celodnevni eks -kurziji. Glavni cilj prve je bil svinčevo-cinkov rudnik olkusz

Verjetja, ki so »mitološka«, ne-trivialna in morebiti » ekso -tična «, potemtakem delujejo na tej ravni, na ravni velike :

SWEET REVENGE (Charlotte Brandstrom). Žena svojemu eks -soprogu najame ljubico, da bi se znebila plačevanja alimer

jutri. Postaneš na primer eks - Jugoslovan ali pa se razglasiš za eks - komunista."

: le še nepomembna formalnost, saj se je vlada R Slovenije, prek eks -ministra za znanost in tehnologijo dr. Petra Tanciga, dogor prigodo, vredno slehernega nabildanega, kvadratnočeljustnega eks -varuha zakona v havajski srajci. Po eksploziji barke se zna əma Gibson/Glover \& s tem tudi glavni negativec filma je namreč eks -policaj, zdaj psihopatski gangster, ki prikoraka v policijskc nico, Ljubišo Samardžiča v vlogi Marlovškovega asistenta, sicer eks -soldata JNA, Borisa Cavazzo v vlogi skorumpiranega polic c Železnik iz Novega mesta sta edina dolenjska predstavnika na eks -temporu, ki sta dobila nagradi za dobro umetniško stvarite a shema krogov, ki zloženi drug v drugega predstavljajo makro-, ekso -, mezo- in mikrosisteme s primeri, ki se nanašajo na šols ? ŠAli ne bi bila pečenica čisto dovolj?', temveč? « » Imate pa zelo eks -kvi-zi-ten okus, milostljiva. « Bravo! « je zaklicala Hedwig 
/anje določetražniku nastopata med dru- spomina na fojbo in na ekso - je pred kratkim napovedal, da nih bolečih plati nedavne। :ras, za dobro mero pa še Maria Conchita Alonso in trije evropski eks -zvezdniki, Jan Niklas, Armin Mueller-Stahl in Vanessa Red so ji kot odgovor na v Italiji uvedeni Dan spomina na žrtve fojb in ekso -

rega potem družno, zelo voajersko opazujeta in zalezujeta svoja eks -ljubimca, po potrebi pa tudi skrivaj - z vsemogočimi trki in som bodisi Marijo v poziciji objekta božje ljubezni oziroma volje. Eks -statičen položaj mistikov, med katerimi so prevladovale ž€ Seveda to ni esej o pop kulturi eks -komunističnih držav. Ker pa globoko verjamem, da je pop I vnikov. Ob konzervativno oblikovani Minici in štirisedežnih iju in EK -Wagonu imajo Japonci v tem malem razredu s Pajerom Min Da sem naiven, mi je četrt stoletja govorila zdaj že eks -sopotnica, ker da so zame vsi ljudje dobri. In da kaj se čud V režiserja in scenarista Davida Mirkina, nista film, v katerem bi eks -maturanti prepevali "oj, mladost, ti moja", ampak film, vk

Tableau 3-eks

\section{ekso-}

Dans les exemples, eks se mélange avec ekso- qui est beaucoup plus rare avec ses 7 occurrences (voir le tableau 4), surtout en opposition (ekso- in endokrini, exo- et endocrines). Ekso n'est pas productif.

Prikazujem 1-7 od 7 konkordanc.

nne so trebušna slinavka (pankreas) in spolne žleze, ki so hkrati ekso - in endokrini, svoje izločke pošiljajo torej navzven in istoc dilo z besedami "večjo", "manjšo", "reaktantov", "produktov", " ekso ", "endo", "segrejemo", "ohladimo", "levo", "desno" (mar »Jaz sem eksponat. Ej, mene slikaj, jaz sem esko... ekso ... eksponat, pizda! « se postavlja Ben s steklenico piva v r rid- ni spremljajo tekmo. Ni druge rem se noter... ljudi ogromno, ekSo podložniki njenega veličanstva res tako nori na nogomet’ rov več novih informacij (vsebin). V letu 1999 smo ustvarili 2 EB (ekso byte alj dva milijona tera bytov), v letu 2002 pa 5 EB novir əndar zagotovo premaga konkurenco. Z izjemo nekaj osamljenih ekso -Jupitrov, je večina znanih eksoplanetov preveč masivnih ıve najdbe je mogoče sklepati, da ima najbrž vsaka zvezda svoj ( ekso )planet, po možnosti več njih. Od petine do polovice zvezc

Tableau 4- ekso

\section{hiper-}

Le préfixe hiper apparaît dans 414 cas parmi lesquels il y a 127 occurrences comme hiper-, avec le tiret, dont 26 avec la majuscule et 6 avec les capitales (HIPER) (voir le tableau 5 ci-dessous). La préfixation s'exerce aussi bien avec les adjectifs qu'avec les noms : hiper-in supermarket (hyper- et supermarché), etno stil in hiper-dekorativnost (le style etno et hyper-décorativité), hiper-informacijska (hyperinformationnel), hiper-kinetičen (hypercinétique). 
Selon le sens des occurrences, nous pouvons voir qu'il y a quelques nouvelles formations (hiper-povezan (hyper-connecté), hiper-povezljivost (hyper-connectivité) dans le tableau 5 ci-dessous, donc la forme est peut-être en train de devenir productive avec les emprunts ou leur traduction vers le slovène.

Prikazujem 21-40 od 127 konkordanc.

Gamble, se jih je oprijel izraz soap. Ker je šlo v njih za ekscesne, hiper -melodramatične štorije, hjah, bistveno večje od življenja čedalje bolj prepletata. Od esencializma preko etno stila vse do hiper -dekorativnosti; to smo videli na modnih revijah pred dob Jravljenju obolenj ščitniv tej številki Misterijev so sodelovali: ce: hiper - in hipotiroze, nodulov na ščitnici in pa seveJože Vetrov€ glavni izraz izpostavljajo skupinske performanse, ki tematizirajo hiper -kinetične pokrajine današnje tehnizirane družbe. Cantsiı e, iste prozornosti, iste potrošniško-tehnološke, kompjutersko- hiper -informacijske, televizijske psihoze, v kateri so vsi krivi z: Prijetna za poslušanje, prav res. Nežna, mehka in kljub slogovni hiper -korektnosti dovolj barvita, da poslušalke in poslušalce p vah srednje in vzhodne Evrope, lahko ponaša z največjo gostoto hiper - in supermarketov na milijon prebivalcev v srednji Evropi Tako se zdi tudi meni. Sigurno živimo včasu hiper -individualizma, čeprav vse dokazuje, da ta način življenj: . Podpisani sporazum zajema Fozzyjeve markete vseh velikosti ( hiper -, super- in minimarkete) in diskontne trgovine s živilskim sodnebnim spremembam in individualnost. Svet je vsak dan bolj hiper -povezan, saj je bilo kar 2,8 milijarde ljudi v letu 2016 že p ikov prihodnosti, so demografske spremembe, nove vrednote in hiper -povezljivost. Vrednote, ki se bodo vedno bolj uveljavljale Induced Topic Search (HITS, iskanje tem oziroma predmetov po hiper - oziroma nadpovezavah), da bi videl, če njegova metoda I za potovanje skozi čas, ki je energijo črnih lukenj izkoriščala za hiper -potovanje s svetlobno hitrostjo. Temu, kar jih pričaka na lanji kapitalistični potrošniški kalifornijski paradiž v svoji izredni hiper -resničnosti v nekem smislu irealen, brez substance, bre: $\vdots-510$ je tisti »bolj« krepko zapisan. Tipalo Live MOS, RAW-zapis, hiper -kristalni LCD, ultrasonični filter, elektromehanski IS - gr :nati. In prav tak avokado je prišel na police omenjenega super-, hiper -, mega- ali kakršnega koli že marketa! Celo solidni pozná teraktivne avtoceste v možgane, agonični, evforični, spektralni, hiper -realni designi seksa in nasilja, snuff filmi. In še dodatna skupaj. Zakaj potem filmov raje ne snemajo po pesmicah, bodisi hiper -literarnih, ponarodelih ali pa rockovskih? Da, filme je mo a Kitajskem diskretno objavili, da bodo polovico prometa vzdolž hiper -ekspresne železniške proge od Pekinga do Tianjina zaup: Poleg vesele blasfemije bi bolj senzitivne gledalce lahko odbilo hiper -kinetično nasilje in slapovi krvi iz odprtih arterij. AMC sic

\section{Tableau 5- hiper}

\section{hipo-}

Du sens contraire de hiper, l'affixe hipo n'a que trois occurrences dans le corpus, dont deux noms : hipoksija (hypoxie), hipo- maxi- in podobnih veletrgovin (hypo-, maxi- et autres hypermarchés) et un adjectif hipo- in hiperbarična terapija (thérapie hypo- et hyperbare) - voir aussi le tableau 6. Nous pouvons constater qu'il est considéré comme 
préfixe dans l'univers notionnel des locuteurs, ce qui découle de son orthographe avec le tiret en opposition avec d'autres préfixes (voir l'exemple ci-dessus hipo- maxi-in podobnih veletrgovin). Mais ce préfixe n'est pas productif en slovène.

Prikazujem 1-3 od 3 konkordanc.

bljajo veliko fizioterapevtskih metod, elektro- in kinezioterapijo, hipo - in hiperbarično terapijo ter druge oblike zdravljenja.

əga zaliva pri-zadelo pridneno pomanjkanje kisika (termoklinska hipo -ksija). To se je pokazalo v meiobentosu s takojšnjim zniža

veli jezika ne pisave, ko so naši predniki shajali tudi brez super-, hipo - maxi- in podobnih veletrgovin, trgovalo pa se seveda je, .

\section{Tableau 6- hipo}

\section{infra-}

Infra comporte 1004 concordances, dont 193 avec le tiret (57 comme infra- et 134 comme Infra). L'orthographe n'est pas stable : infra figure dans les mots avec ou sans espace (infra rdeč (infra rouge) avec 112 occurrences ou infrardeč (infrarouge) avec 4663 occurrences. Ce n'est pas un préfixe productif (pour plus de détails, voir le tableau 7 ci-dessous).

Prikazujem 201-220 od 1.004 konkordanc.

$1151 \quad x$

e, da so električne naprave $v$ kabinah pomemben del preiskav in infra grelec igra v teh preiskavah zagotovo določeno vlogo, ver !e od vsega začetka všeč, saj migaš, torej kolesariš, zraven pa ti infra lučke pomagajo pri razgradnji maščobnih blazinic. Na ob€ sija za transport in promet: Skupno poročilo o osnovni prometni infra -strukturi, delovno gradivo, 1985-86.

pa še Running Up That Hill (priredbo Kate Bush) ter Post Blue in Infra -red. Placebo so tako na primeren način sklenili zaključni 'asi, bodo jeseni odprli še sodobni savna center s turško, finsko, infra in zračno savno ter bazeni za kneipanje. Masažni salon, k /ojka Sotoška je imenovala na mesto direktorja javnega podjetja Infra za obdobje štirih let, in sicer od 9. novembra 2015 do 8 . nı e posnetke napravi ponoči, s pomočjo bliskavice. Uporablja tudi infra rdeče filme in teleskopske objektive."

3. 7 Id., »Država«, v: id., Zbrana dela, I, op. cit., III, 411a6-8. 8 Cf. infra, str. 107-114.

Tukidid, I, 21, 1, 22, 4. Cf. infra , IV. poglavje. 71 cf.: R. Drews, The Greek Accounts of East Local Chronicles of Ancient Athens, Oxford, 1949, str. 216. 98 Cf. infra , str. 145-146.

:ojno in neodvisno. S projektom preverjata tudi možnosti novih ( infra )strukturnih, organizacijskih in socialnih modelov ter opoz e discorso nell'Atene delle professioni, op. cit., str. 52-87. 89 Cf. infra , str. 120-126.

elektrarne (HSE), Hidroelektrarnam na spodnji Savi, podjetjema Infra in CGP Novo mesto, Zavarovalnici Triglav in zdaj že pokojı * Cf. infra, str. 109-110. Hkrati je to smiselno povezati z Avguštinovi ket ob 15 igralcih tudi eno igralko, in sicer Mojco Janc iz podjetja Infra Sevnica, poleg nje pa so zaigrali še sevniški župan Kristij; 
Is končno povezan z rondojem v Boštanju. Predstavniki podjetja Infra in Občine Sevnica so se posvetovali glede dodatnih uredi I na podlagi naročila s strani prometnega ministrstva in podjetja Infra, ki je ob izgradnji elektrarn zadolženo za ureditev spremlj: te pri prometnem ministrstvu, Ana Gračner, direktorica podjetja Infra, Robert Kuzman, izvršni direktor za nizke gradnje pri druž ıtok in potok Kamenca. Tretja podpisana pogodba med podjetji Infra, Direkcijo RS za ceste in družbama Nivo Celje in CGP Novı Javno podjetje Infra d.o.o. kot izvajalec gospodarske javne službe urejanja voı

\section{Tableau 7- infra}

\section{inter-}

\section{Plutôt représenté comme préposition latine (avec espace, voir le tableau 8 ci-dessous), inter n'est pas un préfixe productif. Les 618 occurrences comportent des citations en langues étrangères, inter-muscular, inter pares; de plus, Inter avec une majuscule, pour désigner un club de foot, a 17082 occurrences mais dans ce cas il s'agit d'un nom et non d'un préfixe.}

Pugnant ergo inter se mali et mali; item pugnant inter se mali et boni, si perfecti sunt, inter se pugnare non pos: obrnjenec" Tony Blair odločil prevzeti vlogo evropskega "primus inter pares". Britanski kontingent, ki obsega 6800 vojakov v M Tako se pred današnjim slovenskim derbijem inter lige v Podmežakli sprašujejo navijači obeh ekip, odgovor , samo smer, v katero se je točka premaknila. Na tem je temeljila inter -frame kompresija ali sistem stiskanja med sličicami (v ča Jdlomki: Kritika transparentnosti) - 21.00 Stekleno oko (radijska inter -aktivizacija) - 23.00 Koncert: Ist Annual Texas speed tria Primer: Voda je primus inter pares med pijačami. No, primus inter pares je lahko tudi $६$ a, ki pa vseeno postreže s prepričljivimi etudami, od glasbenega intra DJ Piera, plesnih delov Gregorja Kamnikarja in improvizac zarisal western (Goli v sedlu, Thelma \& Louise). Science-fiction: inter -galaktična iskanja novih svetov (Osmi potnik, Planet opic MURSKA SOBOTA, 22. - V tretjem krogu mednarodne inter lige s standarno puško, kjer sodeluje 13 ekip iz Avstrije, H a (npr. trema) pa lahko izraz moči zavrejo, ker povzročijo intra in inter mišično nekoordiniranost (znotraj mišično in medmišičnc no stranko ne nanaša. Sodna odločba učinkuje med strankama ( inter partes) in tudi pravnomočnost se nanaša nanje (1. odstav

$$
<\text { (char) Vsak char na začetku besede }<\text { (inter ) najde »interesting « in »intercept «, ne pa »splintered « }
$$

ults were normalised with regard to body mass and the relevant inter -muscular and intra-muscular ratios were calculated. The small and fall below $10 \%$ in all types of contraction. The classical inter -muscular ratio HQR (hamstring/quadriceps ratio) was $65^{\prime}$ aasneje tudi svoje šolske cilje, izbrali ustrezen poklic in osvojili " intra in interpersonalno adekvatnost" (prav tam, str.5-6). Teori ilhuete občasno ustvarja tudi na Mostu mestnih vedut. Različne inter - na Soči (ob jezeru stoji njegova pretacije posredno razkr 
za kralja sodobne profane operne umetnosti. Vsaka plošča od » intra « do epiloga uglasbi kako gotsko štorijo, v kateri bi drugač !m državnem prvenstvu, v kateri ta čas zaseda drugo mesto, in v inter ligi štirih držav (Slovenije, Hrvaške, Slovaške in Madžarsk tranet kot strateško poslovno orodje so v sredo podelili nagrado intra za najboljši intranet leta v Sloveniji. Nagrada je pripadla p

$$
\text { Tableau } 8 \text { - inter }
$$

\section{ko-}

Avec ce préfixe, l'analyse détaillée n'est pas possible ; le préfixe $k o$ - est un homonyme de la conjonction $k o$ (quand). Un parcours des exemples montre que $k o$ - figure dans les emprunts mais n'est pas productif en slovène. Ko- en tant que préfixe apparaît dans les cas suivants : kobranding (cobranding), koprodukcija (coproduction) mais il n'y a pas de nouvelles formations en vue avec les mots d'origine slovène.

\section{kontra-}

Le préfixe kontra- (écrit avec le tiret) a 69 occurrences tandis que kontra en a 699. Le mot kontra, polysémique, est aussi utilisé en tant que nom, sa forme familière signifiant le contraire. Les occurrences avec le tiret représentent des noms et des adjectifs composés, leur productivité est démontrée par les exemples suivants, comprenant les noms et les adjectifs (les deux derniers) : kontra-blago (les marchandises de contrebande), kontra-ekvivalent (contre-équivalent), kontra-miting (contre-réunion), kontra-Jelinčič poslanec (le député contre Le Pen, pour une traduction trans-culturelle), kontra-špijonski (de contre-espionnage). Pour plus d'exemples, voir le tableau 9 ci-dessous. Kontra en tant que préfixe est, vu sa combinaison avec les noms propres et les lexèmes slovènes, productif. 
şa slika: časnikarka v Londonu poizveduje o britanskem sistemu kontro -

n. Trenutno je šef gospod Sašo Lap, doslej bolj ali manj znan kot kontra -Jelinčič poslanec. Sobotni zbor je bil zanj prvi nastop n a, libertinska romantična komedija v ritmu dolge, počasne reke, kontra -emtivijevska verzija Sna kresne noči. Rivettu, že tradic lassacre, Bloody Mama) kot v ciklusih o delinkventski rock'n'roll kontra -kulturi (Rock All Night, Sorority Girl, Carnival Rock, Tee ! tatu! « Spoštovani dr. Rupel, v tem primeru ne gre več zgolj za » kontra -faktičnost«, kot zavržen sociološki pojav, gre za Vaše z mitrij Rupel očitno sam nima poguma javno pojasnjevati svoje » kontra -faktičnosti«, čeprav ta zavržni sociološki pojav vehem€ əm svetu. Zvezda je rojena. New York, New York je spektakularni kontra -mjuzikl, že kar post-mjuzikl. Ko De Niro na koncu po njє resti - huh, ali pa tega samospoštovanja. Prej narobe, Murphy je kontra -Fields: iz komika, ki je slovel po mastnem, pikantnem, iji niso pripravljeni deliti z nikomer; Arnold Schwarzenegger je le kontra -psy-avtomat - najbolj mu gredo na živce ljudje, ki skušı Jkoli nabave in zasvojenosti. Heroin je ultimativno kontra-blago, kontra -ekvivalent denariu. Usodni izenačevalec.

\section{Tableau 9- kontra}

\section{meta-}

Le mot meta sans tiret est polyphonique : il désigne une plante, la menthe, et l'affixe d'emprunt, meta. L'orthographe avec le tiret met en évidence les possibles préfixes : il y en a 220, le préfixe est vaguement productif : meta-etika, meta-film, meta-jaz (méta-ego), meta-SP (méta-professionnel indépendant). Pour plus d'exemples, voir le tableau 10 ci-dessous.

ıkvarja posebna podzvrst deskriptivne poslovne etike: poslovna meta -etika.

ir se je preime-novala provotna krščanskosocialna struja. Njune meto -de delovanja so bile enako ilegalne kot tigrovske, ven-da ıstlino. Denimo v Zgornji Savinjski dolini so najboljše za poprovo meto - iz pridelane smo dobili veliko eteričnega olja; poprovo n Poprova meta - 3 prgišča posušenih listov poparimo z 1 litrom kropa in ।

k, da vidiš vse. Spektakel je vse, kar ogroža človeški pogled. Ja, meta -film. Okej, kaj drugega pa naj pričakujemo od bratov Coe man nadaljuje: »Ker pa je vse njihovo delovanje tako ali tako bolj meta -fizično kot fizikalno, je po mojem njihov odnos do prej on vto-referencialnost preučevanja kulture,36 kar Mulhern imenuje meta -kultura: v njej naj bi bila »kultura objekt svoje lastne refle sdpira široko polje asociacij in metafor. Za končni "še in še" se v meta -fizično počasi naseljuje individualno. Čestitke.

skim ministrom Naumanom, ki meni, da bi morali govoriti o neki meta -indentiteti; če je to namreč nekaj čez identiteto, potem t n izdelku. Sodišče je zato prepovedalo navedbo tega produkta v meta -tagih vseh spletnih straneh, ki nimajo nikakršne neposr€ Jrugega, pa je moja metaidentiteta. To gre lahko v neskončnost: meta -meta-meta perspektive, metameta-meta identitete ... M skupino in jo sidramo kot enoto za samopomoč. Tako ustvarimo meta -SP, ki z združenimi močmi deluje v prid našega zdravja. čni, nadrealistični, morbidni, baročni, kapriciozni, halucinantni, meta -morfni fleš, poln ust in oči v velikih planih, ki grozijo, da $t$ 
nas pripelje do komedije Bes pod kontrolo, ki ni nič drugega kot meta -film o Adamu Sandlerju. Reč je tako didaktična, da se pril anstvenikov varovali pred rakom. Nevrobiolog Paul Sherman je v meta -analizi 646 raziskav, objavljenih v zadnjih 50 letih, prišel rivlačila skupinska naloga in skupina sama kot socialna enota. V meta -analizi, ki so jo izvedli Carron, Hausenblas in Mack (1996 eko intervencij znatno povečati. To je bilo prikazano z obsežnim meta -analitičnim pregledom. Pokazala sta, da so bile intervenı , o katerem govorijo apostoli. Vsekakor je na bojni nogi z vašim ' meta -jazom'. Ego se istoveti s tem lažnim omejenim jazom, z v Idealno je, če študij preobrazbe in meta -človeka nadzoruje dobro poučen vodnik. Takšni učitelji s

\section{Tableau 10- meta}

\section{post-}

Le lexème post entre en jeu avec le post qui est, comme meta, polyphonique et, dans ce cas, vérifiable seulement avec le tiret (sans tiret, il signifie le jeûne). Post- apparaît surtout avec les adjectifs post-socialističen (postsocialiste), post-komunističen (postcommuniste), post-travmatski (post-traumatique), plus rarement avec les noms (post-punk). Les exemples montrent qu'il est employé surtout dans les emprunts, mais peut être aussi productif (post-rokodelski, post-artisanal). Pour plus de cas, voir le tableau 11 ci-dessous.

na pustolo- ulični glasbenik Poskočni Jan, vščino - iz teme pod poste - ki postane njegov novi prijaljo rešita nekaj nekdaj naj- t jivejši kontejnerski dvigali STS (Ship-to-Shore), dimenzije super post -panamax, s katerima bodo lahko pretovarjali zabojnike ne eti so opustili svoj prvotni zvok, v katerem je še bilo slišati nekaj post -punk primesi, ter zajadrali v bolj elektronske vode in dos€ ki jo od konca hladne vojne riše za MTV, nikoli ni bila samo stvar post -hladnovojnega prijateljevanja diplomatov. Pa tudi za drug času zalivske vojne (Pleše z volkovi). War Party (1989) je tipičen post -vietnamski western: po eni strani resda predstavlja paraf :riferno. Breakdown zelo lepo, tako rekoč šolsko ujame sodobno post -feministično, neo-patriarhalno percepcijo ženske, ki je le Post -truth, poresničnost, je Oxfordski slovar razglasil za besec New Art Practice). Je ena od pionirk sodobne videoumetnosti in post -konceptualne kritične umetnosti. Sodelovala je na pomer čustev. To ni nekaj, kar lahko preboliš. Kot da bi šlo za nekakšen post -travmatski stres. Vseeno pa njegovo življenje ni povsem t rju predstavila Brina s skupino sodobne improvizirane glasbe in post -akustične jazz in etno glasbe, na Lisci pa etno jazz zasedl 
Jredpozicionalni odnos do evrocentrične dobe, ki se je končala (post -) ali pa se še ni začela (pred-). Drugače povedano, številn ronski odnosi, še vedno nekatere primere rokodelskih in mnogo post -rokodelskih razmerij; ta zadnja so pogosto ostala v svoji । h delih tradicionalne glasbe še vedno prevladujejo distribucijska post -rokodelska razmerja, medtem ko je pri popularni glasbi žı Notranje spremembe $v$ produkcijskih post -rokodelskih odnosih v književnosti so zlasti pomembne z

\section{Tableau 11- post}

\section{pro-}

L'affixe pro avec ses 1559 occurrences ne donne pas beaucoup d'exemples qui démontreraient sa productivité. Parmi les exemples figurent surtout des citations : pro vida (13 occurrences), pro rata (38), pro life (62), pro-choice (28) et pro-licenca (98), Pro TV (99 occurrences) où il est visible que pro signifie pour, mais aussi professionnel. Le premier sens est visible dans l'opposition pro- in kontra (pour et contre) avec 2 occurrences.

\section{re-}

L'affixe re est problématique - avec le tiret, on peut isoler quelques cas où il figure comme préfixe : re-in deteriorizacija, re-break. Dans la plupart des cas (cités aussi dans le tableau 12 ci-dessous), il ne s'agit pas du préfixe mais de l'emprunt du mot commençant par re (reaktiven (réactif), etc.)

Prikazujem 41-60 od $\mathbf{1 . 2 8 3}$ konkordanc.

i se lahko, če ji uspe, tudi sama deteritorializira v svetu. Procesi re - in deteritorializacije, standardni repertoar filozofskega apaı

Serija zvočnih dogodkov Re -lax svojo tretjo sezono začenja v sodelovanju z renomiranin

1. Menja pač razpoloženja. Saj veste, ciklusi. In to bi-cikliranje in re-cikliranje ga peče, boli, skeli, trpinči in razjeda.

ednji naredil dve dvojni napaki in dovolil Italijanu, da je prišel do re -breaka in znižanja izida na 1:4. Tudi v naslednjih dveh igrah $\varsigma$

nega dela in šele na tej osnovi lahko pričnemo govoriti o njegovi re -snični, umetniški moči.

li bankine. Vem tudi za čisto vsako udarno jamo na cesti in lahko re -

a prednosti ni mogla zadržati, saj je Kerberjevi ekspresno uspel re -break. Niz se je prelomil v 7. igri, ko se je Kerberjeva znašla v

katastrofalen izdelek z naslovom Load, leto za njim pa še slabši Re -load, ki, kot pove že naslov, ne počne nič drugega kot prodi ıpina Interceptor. Intenzivno potekajo tudi priprave na jesensko re -union turnejo. Na tokratnem uvodnem koncertu bodo snem: u poraza tudi v drugem. Toda v odločilnih trenutkih jima je uspel re -break in izsilila sta podaljšano igro, ki sta jo tudi dobila.

:rviral za vodstvo 5:3. A se je Argentinec že v naslednji igri vrnil z re -breakom in poskrbel za navdušenje navijačev na polnih tribı OO Euronews - 16.20 Anthony: Uporni umetnik,. angl. film, 1960; re -ija Robert Day, igrata George Sanders, Paul Massie - $18.00 \mathrm{~F}$ 
e Skupine Era, njena ključna dejavnost pa je oskrba sektorja ho- re -ca, to je hotelov, restavracij in katering podjetij. "Naložbenє Elsčve Re -Nutrition iz L'oreala, linija za nego las, obogatena z Royal J, LJUBLJANSKA ART KLIKA ker se je, naštejmo, znotraj cikla Re -Lax, Foo Bara v Moderni in dogodkov v Kapelici pridružila of I nadzorovalnih mehanizmov), ne nazadnje tudi zato, ker je zgolj re -aktivna, tj. omejena na odzivanje na določena problematičn - Madonnina turneja Re -Invention ni postregla samo s pregrešno dragimi vstopnica niku, potem ko je ta žogico poslal v mrežo. Beograjčanu je uspel re -break, a se je Murray še drugič vrnil v dvoboj, Srbu preprečil

Tableau 12-re

\section{sin-}

En tant que préfixe, il n'a pas d'occurrences dans le corpus (son homophone sin, le fils, prévaut dans le corpus).

\section{sub-}

Le préfixe $s u b$ - avec un tiret a 134 occurrences. Sub entre en opposition avec super : subin super (sub et super), sub-, retro- (voir le tableau 13 ci-dessous) mais concerne aussi et surtout les emprunts aux orthographes variables sub-woofer et subwoofer (le premier avec 3, le second avec 182 occurrences) ; subregija (138 occurrences), subkultura (2282 occurrences). Il n'est pas productif, il n'y a pas de nouvelles formations avec la base slovène.

Prikazujem 1-20 od $\mathbf{1 3 4}$ konkordanc.

of the 6th Sym-posium of Confederation Mondiale des Activites sub -aquatique, Natural Environmental Research Council: $167-1$

a, tako kot so bila že prej razrešena razmejitvena vprašanja med sub -držav-nimi enotami, posestvi in polji. $v$ bistvu pa nadome, med drugim pa ima v ohišju monitorja vgrajene tudi zvočnike in sub -woofer. Računalnik bo prišel na prodajne police konec avg raza kulture. Prvi je izklesan z ideološko resnico, ki je temelj ali sub -iectum kulture, zelo strogo in nepopustljivo obvladuje vse ovskih turbulencah, ki jih je povzročila kriza v tako imenovanem sub -prime segmentu ameriškega hipotekarnega trga, so si teč alect group, or, more precisely, to the western Slovenske gorice sub -dialect. Two typical features of this speech are the loss of na drugi, ki se torej odloči med alternativno ponujenim mestom sub -jekta v pogledu Moči za svojo tretjo in specifično pot. Gno: $\therefore$ one minule dobe (kolikor sta kompatibilni s predponami alter-, sub -, retro-) vidita avtorja pripravo in napoved instalacije slov Jgeniji Y kromosoma, ki se pojavlja izključno v Evropi. Njena dva sub -klada I1a in I1b* izkazujeta največji zgostitvi v Skandinaviji re žanre popularne glasbe, ključna vprašanja popularne kulture, sub - in mladinske kulture, vlogo glasbe v sodobni družbi in upc łktorju gradbeništva in gradbenih materialov je vsebina projekta sub -contracting. Zanj je Gospodarska zbornica Slovenije 7. ma Ičetka je na voljo šest služb, ki imajo po odklenitvi sposobnosti ' sub -job' devet mogočih podpoklicev v slogu dual classinga iz [ 


\begin{abstract}
voljo tudi modeli, ki so na meji sprejemljivosti - tako imenovani sub -notebooki, kjer so komponente stlačene v najmanjše mož ' zaradi intencionalne dejavnosti bolj imuni na neintencionalno " sub -kvantno ohlajevanje". Svobodne voljne dejavnosti torej na ko radi vse poimenujejo, so takoj začeli govoriti o novem trendu sub - \$1000 PC-jev. Pa trend v resnici ni dolgo trajal, kajti pred । J prejeli prof. dr. Željko Knez za izpopolnitve procesov ekstrakcij sub - in superkritičnih tekočin, prof. dr. Janez Možina za raziski u, ki ga bo istega večera mogoče slišati tudi v zasedbi MTF feat. Sub -Lime. V nadaljevanju pa bodo nastopili tolkalca Aleš Rend ion in the following way. From the initial sample, we created ten sub -samples with 592 bankrupt firms and their 592 non-bankrı denarja pod nerealnimi pogoji. V glavnem gre za tako imenovani sub -prime market. To je posojanje denarja, večinoma kot izdaj:
\end{abstract}

Tableau 13-sub

\title{
super-
}

Le mot super est polysémique - il fonctionne comme adverbe et comme affixe. Dans le cadre de ses 363640 concordances comme affixe, il est le plus vérifiable dans son rôle d'affixe avec un tiret super- : super-delegat (superdélégué), super-G, supernova et son synonyme super-velikanka, super divizija (superdivision); les syntagmes avec le plus grand nombre d'occurrences sont super Bowl (722), Supernova/supernova (2460), super-G (66). Quant à sa productivité, elle est démontrée dans les exemples adjectivaux super-mehek (supersoft), super-lahka (extra-light), ou nominaux super-hrana ou superhrana (supernourriture ; 2 occurrences pour la première, 77 pour la deuxième).

kov, ki z navdušenjem pritiskajo na plin in vozijo njihov najljubši super -avto po sloviti stezi velike nagrade Monte-Carla. Seveda Štart super -G-ja je bil na 1340 metrih nadmorske višine, cilj v areni F in simbolna zgradba. Je osrednji del, pravo srce mesta Weston- super -Mare," je za Sky News izjavil župan mesta Andrew Horle I kristalnega globusa za zmago v skupnem seštevku. V seštevku super -G si je prismučala drugi mali globus (2014, 2016) in ob oc o naravna varovalna sredstva brez karence, kot sta bio plantella super - $f-R$ in natur-f.

:rde, bio plantella arion plus in bio plantella natur-f, bio plantella super - $f$... ALI SO TO vSA?) Tako varovane in gnojene vrtnine pa I osmimi leti le 131 izvoljenih delegatov več kot Clintonova in 105 super-delegatov. Clintonova tokrat ni hotela ničesar prepustiti ya nasprotnika na obzorju, si je takoj zagotovila zvestobo večine super -delegatov. S Sandersom sta si sicer porazdelila zmagov vanji dobila 1812 delegatov, poleg njih pa še 571 tako imenovanih super-delegatov, to je strankarskih veljakov, ki se odločajo po akrat nobeden ni premislil. Neodločenih je ostalo le še 95 od 714 super-delegatov. Delegati bodo na konvenciji potrdili strankar: Iris, uporabimo pa lahko tudi pripravek iz programa bio plantella super - $f-r . v$ deževnih letih jih napada nageljnova rja in nageljnc ajo več. Teorija pravi, da so se vse oziroma skoraj vse, rodile kot super-velikanke, več stokrat bolj masivne kot je naše Sonce. $\mathrm{K}$ dnji propad pa je bil zelo dober za nadaljnji razvoj vesolja, saj so super -giganti v vesolje izbruhali težke elemente, potrebne za r 
rand Prix v Heilbronnu - 15.00 Ekskluzivno: moto šport, D1 ADAC Super -Cup $96-16.00$ Motociklizem: SP v speedwayu v Pockin terimi so privilegirale svoje ekonomije in tanek sloj bogatašev ( super-razred «), revni svet pa s svojimi političnimi odločitvami a časnik je Inzaghiju namreč dodelil oceno devet in ga označil za Super -Euro-Pippa. Kakršenkoli vzdevek že ima, Inzaghi je v fin ov). Menjalnik ima $27+27$ prestav, s tem da je 9 najpočasnejših ( super -reduktor) pri pnevmatikah $659 / 65 \mathrm{R} 38 \mathrm{v}$ razponu hitrosi :rs lahko v tem primeru zmaga le, če uspe prepričati več kot 500 super -delegatov, da zapustijo clintonovo in stopijo na njegovo ni le v Val d'Iseru, ko je osvojil četrto mesto. Peti je bil dan prej v super-G-ju. 25-letni Mariborčan je prišel do tretje najboljše sm

\section{Tableau 14- super}

\section{supra-}

Supra n'apparaît que quatre fois dans le corpus avec le tiret. Sinon, ce mot a 127 occurrences dont la plupart correspond à l'appellation super (pour le carburant), au génitif, dans le registre familier (super, supra). Il y a un nom propre, Supra-stan, avec 24 occurrences. Ce préfixe n'est pas productif.

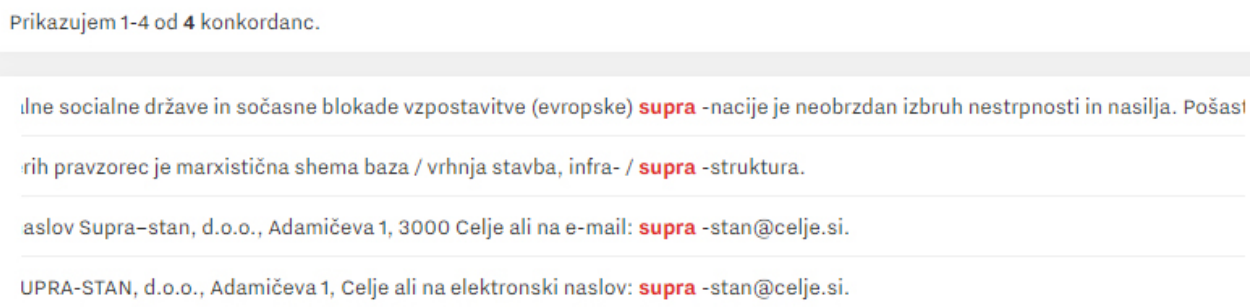

Tableau 15- supra

\section{trans -}

Le lexème trans est polysémique, il signifie la transe et aussi l'affixe trans- (qui traverse) devenu très fréquent en slovène grâce à quelques syntagmes adjectivaux et nominaux : trans-maščobni ou transmaščobni (426 occurrences) et trans-maščoba (acides gras trans) 206 occurrences), transspolni (transsexuel, 371 occurrences), transsibirski (175 occurrences), transatlantski (773 occurrences). Trans avec le tiret présente 441 concordances, trans en totalité, tous usages confondus, en présente 3944. Ce préfixe est vaguement productif, lié à quelques collocations avec un grand nombre d'occurrences. Voir aussi le tableau 15 ci-dessous. 
pus Dei (1987), Let it be (1988), Macbeth (1990), Kapital (1992) in Trans -Slovenia Express (1994).

in) v krvi ("slab" holesterol) bolj kot nasičene maščobne kisline. Trans -maščobne kisline so običajno prisotne v margarini zarac 'sebnosti večkrat nenasičenih (poli) maščobnih kislin (PUFA) ter trans -maščobnih kislin. $v$ tabeli, ki smo jo izdelali v sodelovanj Ja v margarini in v drugih vrstah maščobe ni več kot en odstotek trans -maščobnih kislin (na Nizozemskem) oziroma manj kot 5 , smo ocenili tiste vzorce margarine, ki vsebujejo nad $1 \%$ do $5 \%$ trans -maščobnih kislin, kar pomeni, da je tveganje za zdravje s tor), ocena za margarino Rama pa se je zaradi majhne vsebnosti trans -maščobnih kislin izboljšala in je skupno "zadovoljiva". Pı ;ti je seštevek obeh kriterijev, pri čemer ima večjo težo vsebnost trans -maščobnih kislin.

Projekt Trans -formation obsega razstavo psihofotografik Branka Baćo Rapp Trans -Ipmit naj bi bil po številu referenc prepričljivejši od konk ıme skupine sicer veljajo The Man-Machine, Computer World in Trans -Europe Express. Lani je po sedemnajstih letih premora i. vduševal, ker mi je bil David Hasselhoff zoprn, ampak Pontiacov trans - am z rd J Trans-formation avtorjev Branka Baćovića in Davida Hollerja. $v$ Trans -formation zbrane pesmi obeh avtorjev, ki so napisane v : zomernih oblikah: cis-butendiojska kislina (maleinska kislina) in trans -butendiojska kislina (fumarna kislina). Maleinsko kislino nalih narcizmov in kratkih poti. V resnici je ena izmed atrakcij te trans -mreže. Njegove knjige so akademski bestsellerji, njegov Francozov ni presenečenje, saj so bili podrejeni. Finci so igrali v transu - kot roj kamikaz. Njihova obramba je videti zmedena, v Ivenščini "dolgočasen"), je mesto v Oregonu, ki se je odločilo za trans -atlantsko turistično in humorja polno potezo - pobratilo। ambo pri sobnih temperaturah. Žal pa so študije pokazale, da so TRANS -maščobe še bolj nezdrave kot navadne nasičene mašč

\section{Tableau 16- trans}

\section{ultra-}

Ultra aussi est polysémique et se présente comme adverbe ou comme préposition ou préfixe. Le préfixe ultra- est productif : avec le tiret, il est uni avec des lexèmes slovènes adjectivaux ultra-novi, ultra-nizek, ultra-ortodoksni, et nominaux ultra-tekači, ultra-kolesarji. Ultra présente, dans les deux derniers exemples, l'ellipse pour ultramarathon. Il est aussi employé en opposition : ultra- in infraobmočje (la zone ultra- et infra).

Prikazujem 1-20 od 247 konkordanc.

čila »drugo rojstvo «, s katerim bi postal nekak post-holokavstni ultra -cyber born-again - njena paranoična pro-life fantazija pa Marko Baloh je vrhunski ultra -maratonski kolesar, ki kljub astmi dosega zavidljive uspe voje letošnje uspehe. Kljub močni konkurenci sedemindvajsetih ultra -kolesarjev, med katerimi Baloh največjega konkurenta vi m celo šokiral s kvazi-dokumentarnim, insidersko-paranoičnim, ultra -preverjenim, hiper-informativnim in politično-holokavstr Jbre ukrepe. »Toda pri tem bomo zelo pazili, kaj se bo dogajalo v ultra - in infraobmočju, « je še zagonetno dodal vodja poslanceı 


\begin{abstract}
‘eliko reklamo za novo skupino SMOKE CITY, ki je naredila novi " ultra -zvočni" komad z naslovom UNDERWATER LOVE (TTT); ta j 10 mi to ljudstvo, ki to počne. Ko pa sem spoznal skoraj vse naše ultra -tekače, veliko triatloncev in plavalcev, a tudi veliko tujce' rian G. Hutton. Ko je Robert Aldrich posnel cinični, mačistični in ultra -kinetični Ducat umazancev (1967), se je svet spremenil: v ormalno, kombinirano, mastno, suho ali občutljivo kožo čistijo z ultra -učinkovitimi formulami, ki so hkrati tudi nežne in lahke in etejšem judovskem kraju v Jeruzalemu, je izbruhnil spopad, ker ultra -ortodoksnim Judom ni bilo všeč, kako molijo manj ortodc is ves čas žaluje, ker na začetku filma ni preprečil pokola članov ultra -desničarske para-vojaške milice.

at francoskih razpuščencev, zagrizenih skvoterjev, anarhistov in ultra -vegetarijancev, ki jih spremlja petero psov, po volji gospc luetooth receiver. It provides mobile professionals a one-piece, ultra -portable alternative to the touchpad. The mouse features Jmembna za obvladovanje astme, je ekipa 11 kolesarjev iz Leka z ultra -kolesarjem Markom Balohom na čelu v Kranjski Gori zač€ Las Vegas - Slovenski ultra -maratonski kolesar Marko Baloh je zmagal na 31. dirki Sil n dr. Gabriela Byrnea in FBI-ja (Daniel Benzali) eksperimentira z ultra -high-tech sistemom za nadzorovanje, ki bo kameri in mo Posebno tveganje z vidika vplivov na zdravje lahko predstavljajo ultra -fini delci za otroke, mladostnike, nosečnice in starejše ljı skimi igralci, s fokusiranjem spodnjega družbenega razreda in z ultra -nizkim proračunom. Tretji zakon: »neo-filmarji« se zelo ra a najstniške drame Trinajst. In iz filma, ki je hotel postati super- ultra -kul-mega poklon skejterjem, naredila mladostniško dram arjajo z barvno rozeto, ki se vrti pred čipom. 120 W žarnica UHP ( ultra -high performance) ima deklarirano življenjsko dobo 2000
\end{abstract}

Tableau 17- ultra

5 CONCLUSION

Nous pouvons constater que notre hypothèse du départ concernant la (non)productivité des préfixes de composition étrangers dans les noms et adjectifs, ne peut pas être entièrement confirmée. La productivité des préfixes étrangers dans la composition des noms et des adjectifs est plus grande que dans le cas des préverbes (Perko, Schlamberger Brezar 2016). En outre, la productivité est en hausse par rapport à notre recherche dans le corpus FidaPlus entre 2004 et 2006 où seul le préfixe anti- pouvait être considéré comme tel. Dans notre recherche, la productivité est attestée avec les préfixes eks, ekstra, hiper, kontra, meta et super.

Dans la plupart des cas, ces préfixes étrangers sont employés dans des syntagmes particuliers dont le nombre dans le corpus est croissant. 11 est possible que ces préfixes tendent vers la grammaticalisation (voir aussi Schlamberger Brezar 2011) : ils ne sont pas omniprésents mais limités à certaines occurrences qui deviennent très fréquentes (voir le cas de ekstralahek (extra-ou ultraléger), ekstradeviški (extravierge) en combinaison avec les produits alimentaires).

Le statut du préfixe productif peut être démontré par la mise en opposition avec son préfixe contraire (et orthographié avec le tiret) hipo- in hiperinflacija (hypo- et 
hyperinflation) ainsi qu'avec les combinaisons du préfixe étranger et de la racine slovène, nominale ou adjectivale : antilevičar (anti-gauchiste), kontrajelinčič (contre-jelinčič), ekstralahek (extra-léger), eks-policaj (ex-policier).

Si nous comparons le comportement des préfixes étrangers de base comme $a$-, reavec les préfixes productifs comme kontra, super, ekstra etc., nous pouvons constater que ces derniers gardent plus de sens : un grand nombre fonctionne aussi bien comme adverbe et comme affixe (super, ekstra, kontra). En tant que tels, dans l'acception des locuteurs, ces préfixes ont un sens et peuvent donner suite à la formation néologique.

Finalement, le traitement des affixes dans la grammaire, avec l'accès à une analyse de corpus, peut enrichir les données existantes et éclaircir le fonctionnement des préfixes étrangers en langue slovène dans les courants de la mondialisation.

\section{BIBLIOGRAPHIE}

ANDERSON, Stephen R. (1992) A-Morphous Morphology. Cambridge : Cambridge University Press.

ARONOFF, Mark (1994) Morphology by itself, stems and inflectional classes. (Linguistic Inquiry Monograph 22.) Cambridge, MA: MIT Press.

BAAYEN, Harald (1993) On Frequency, Transparency and Productivity. Yearbook of Morphology 1992. 181-208.

BAUER, Laurie (2001) Morphological Productivity. Cambridge : Cambridge University Press.

BEARD, Robert (1995) Lexeme-Morpheme Base Morphology. Albany : State University of New York.

CENTRE NATIONAL DES RESSOURCES TEXTUELLES ET LEXICALES. Source web. https://www.cnrtl.fr. 20 octobre 2021.

CORBIN, Danielle (1987) Morphologie dérivationnelle et structuration du lexique. Tübingen: Max Niemeyer Verlag.

CJVT JEZIKOVNA POLITIKA. Source web. https://jezikovna-politika.si/opremljenost/ jezikovni-opis/korpusi/. 20 octobre 2021.

CJVT VIRI IN ORODJA. Source web. https://www.cjvt.si/viri-in-orodja/besedilni-korpusi/. 20 octobre 2021.

CREISSELS, Denis (2015) Initiation àla linguistique du terrain. 20. octobre 2020 https:// llacan.cnrs.fr/fichiers/cours/Creissels/ling_ter_Morphologie.pdf

DAL, Georgette (2003) Productivité morphologique : définitions et notions connexes. Langue française 140. 3-23.

DESMETS, Marianne/Florence VILLOING (2010) Morphologie constructionnelle et arguments sémantiques du verbe : un traitement HPSG des composés VN du français. Travaux de linguistique 2010/1 (n 60). 65-89. 
DRESSLER, Wolfgang U. (2000) Extragrammatical vs. marginal morphology. Ursula DOLESCHAL/Anna M. THORNTON (éd.) : Extragrammatical and Marginal Morphology. München : Lincom. 1-10.

DUBOIS, Jean et al. (2002) Dictionnaire de linguistique. Paris : Larousse-Bordas/VUEF.

FRADIN, Bernard (2003) : Fradin. Nouvelles approches en morphologie. Paris : Presses Universitaires de France.

KORPUS GIGAFIDA. Source web. www.gigafida.net. 20. Octobre 2021.

MEL'ČUK, Igor A. (1993) Cours de morphologie générale (théorique et descriptive) 1. Montreal, Pariz: Les Presses de l'Université de Montréal, CNRS.

PERKO, Gregor, (2013) La dimension métalinguistique de la morphologie du français non conventionnel. Linguistica 53/1. 209-220.

PERKO, Gregor (2018) Sur les différentes identités de la morphologie constructionnelle en français. NIKODINOVSKI, Zvonko (éd.). Le même, le semblable et le différent au sein de la langue, de la littérature et de la culture dans les pays francophones = Istoto, sličnoto i različnoto vo jazikot, vo kniževnosta i vo kulturata vo frankofonskite zemji : [actes du Colloque international, Skopje, 04 - 05 novembre 2016]. Skopje: Université »Sts Cyrille et Méthode «, Faculté de philologie »Blaže Koneski«: = Univerzitet »Sv. Kiril i Metodij«, Filološki fakultet »Blaže Koneski«. 333-342.

PERKO, Gregor/SCHLAMBERGER BREZAR, Mojca (2016) Tvornost tujih in prevzetih glagolskih predpon v slovenščini. KRŽIŠNIK, Erika (éd.)/ Miran HLADNIK (éd.). Toporišičeva obdobja. Ljubljana: Znanstvena založba Filozofske fakultete. 173-180.

RIEGEL, Martin et al. (1994) Grammaire méthodique. Paris : PUF.

SCHLAMBERGER BREZAR, Mojca (2011) Le gérondif et le participe présent et leur évolution vers la grammaticalisation : étude contrastive du slovène et du français. Linguistica. 51/1. 333-348.

$\mathrm{SP}=$ SLOVENSKI PRAVOPIS. Source web. http://www.fran.si. 20 octobre 2021.

SSKJ = SLOVAR SLOVENSKEGA KNJIZNEGA JEZIKA. Source web. http://bos. zrc-sazu.si. 20 octobre 2021.TOPORIŠIČ, Jože (1992) Enciklopedija slovenskega jezika. Ljubljana : Cankarjeva založba.

TOPORIŠIČ, Jože (2000) Slovenska slovnica. Maribor : Obzorja.

WIKIPEDIA. Source web. https://sl.wikipedia.org/wiki/FidaPLUS. 20 octobre 2021.

POVZETEK

\section{TVORNOST TUJIH PREDPON V SAMOSTALNIŠKIH IN PRIDEVNIŠKIH ZLOŽEN- KAH V SLOVENŠČINI}

Besedotvorne operacije so $\mathrm{v}$ tradicionalni slovenski slovnici analizirane v okviru morfematskega besedotvornega modela. Toporišič (2000: 194-195, 200-201) pri zlaganju samostalnikov in 
pridevnikov obravnava naslednje predpone: a, ante, anti, eks, ekstra, hiper, hipo, infra, inter, intra, ko, kontra, meta, sin, sub, super, supra, trans, ultra. Pri leksematskem besedotvornem pristop pa je osnovna enota leksem. V članku tako obravnavi predpon posvetimo v okviru leksematskega besedotvornega pristopa in preučujemo njihovo tvornost na gradivu enojezičnega korpusa FidaPlus med leti 2004 in 2006 in na gradivu korpusa Gigafida2.0.

Raziskava, ki je potekala med leti 2004 in 2006, med predponami odkrije le eno tvorno, anti, v zadnjem času pa se za tvorne predpone poleg anti izkažejo še kontra, eks, ekstra in super, ki se uporabljajo tako s tujimi podstavami kot tudi v obliki novotvorb $\mathrm{z}$ domačimi podstavami. Te domače podstave so lahko lastna imena (antijanša, kontrajelinčič) ali pa tvorjeni pridevniki in samostalniki z domačo podstavo (ekstralahek, ekspolicaj), tvornost predpon pa se vidi tudi pri izražanju opozicijah, na primer hipo- in hiperbarična terapija. Za vse druge predpone pa ugotavljamo, da je tvorjenost v slovenščini bolj ali manj navidezna in da jih je treba v celoti obravnavati kot izposojenke.

Vseeno se na osnovi dveh več kot deset let oddaljenih raziskav pokaže, da ob upoštevanju podatkov iz korpusa lahko vidimo naraščanje tvornosti tujih predpon: če smo v prvotni raziskavi tvornost lahko potrdili le za anti, se je trenutno pokazalo, da so take, vsaj delno, tudi kontra, eks, ekstra, super. Besede, ki so se sprva pojavljale kot neologizmi, so zdaj pa vstopile v vsakdanjo rabo.

Ključne besede: leksematski besedotvorni pristop, tuje predpone, samostalnik, pridevnik, tvornost

\section{ABSTRACT}

\section{PRODUCTIVITY OF LOAN PREFIXES IN COMPOUND NOUNS AND ADJECTIVES IN SLOVENIAN}

The operations of word formation in traditional Slovenian grammar are analysed within the framework of morphematic word formation model. As part of the composition of nouns and adjectives, Toporišič (2000: 194-195, 200-201) lists the following loan prefixes: a, ante, anti, eks, ekstra, hiper, hipo, infra, inter, intra, ko, kontra, meta, sin, sub, super, supra, trans, ultra.

Within the lexemic word formation, the unity is a lexeme. In the paper, the operations of word formation are analysed within the theory of lexemic word formation, particularly with regard to their productivity, based on the data of the monolingual corpus FidaPlus between 2004 and 2006 and Gigafida2.0. The research, carried out between 2004 and 2006 revealed only one productive prefix, anti, whereas recent research showed that in addition to anti, the prefixes kontra, eks, ekstra, and super can function as productive, used with both foreign lexemes and with authentic bases as neologisms. The domestic bases can be proper names (antijanša, kontrajelinčič) or composed adjectives and nouns with original Slovene base (ekstralahek, ekspolicaj), and the productivity of the prefixes can be seen also in oppositions like hipo- in hiperbarična terapija (hypo- and hyperbaric 
therapy). For all other prefixes, the research points out that their composition in Slovene is more or less a matter of appearance and that they should be dealt as loan words.

The two analyses, that have more than ten years between them, show that we can see the growing productivity of the prefixes. If in the first analysis only anti has shown productivity, the second analysis points out that kontra, eks, ekstra, super are also productive. The words that first appeared as neologisms are now a part of everyday language use.

Keywords: theory of lexemic word formation, loan prefixes, noun, adjective, productivity

\section{RÉSUMÉ}

\section{PRODUCTIVITÉ DES PRÉFIXES ÉTRANGERS DANS LES COMPOSITIONS NOMI- NALES ET ADJECTIVALES EN SLOVÈNE}

Les opérations de la formation des mots dans la grammaire slovène traditionnelle sont analysées dans l'approche morphologique morphématique. Dans le cadre de la composition des noms et des adjectifs, Toporišič (2000 : 194-195, 200-201) énumère les préfixes suivants d'origine gréco-latine : a, ante, anti, eks, ekstra, hiper, hipo, infra, inter, intra, ko, kontra, meta, sin, sub, super, supra, trans, ultra. Dans le cadre de la morphologie contructionnelle, l'unité de base est le lexème.

Dans cet article, l'analyse de leur fréquence en tant que mots d'emprunt et de leur productivité est faite dans le cadre de la morphologie constructionnelle au sein des données du corpus FidaPlus entre 2004 et 2006, ainsi que du corpus Gigafida2.0. La recherche, menée entre 2004 et 2006, a révélé un seul préfixe productif, anti, tandis que récemment, les préfixes, pouvant fonctionner comme productifs, sont kontra, eks, ekstra, et super, employés aussi bien avec les bases d'emprunt qu'avec les lexèmes slovènes sous forme de néologismes.

Les bases slovènes sont soit les noms propres (antijanša, kontrajelinčič) ou les adjectifs et noms composés avec le lexème d'origine slovène (ekstralahek, ekspolicaj), la productivité est visible aussi dans les oppositions des préfixes du type hipo- in hiperbarična terapija (thérapie hypoet hyperbare). Pour les autres préfixes, on peut constater que leur composition en slovène n'est qu'apparente et que ces mots composés peuvent être qualifiés d'emprunts.

Tout de même, à la base des deux analyses du corpus distantes de plus de dix ans, on constate la croissance de la productivité des préfixes. Si, dans la première analyse, la productivité n'était confirmée que pour anti, l'analyse contemporaine démontre la productivité, au moins partielle, des préfixes kontra, eks, ekstra, et super. Les mots qui apparaissaient comme néologismes font aujourd'hui partie du vocabulaire de tous les jours.

Mots-clés : morphologie constructionnelle, préfixes d'origine gréco-latine, nom, adjectif, productivité 